\title{
Measurement and correlation of wedged hepatic, intrahepatic, intrasplenic and intravariceal pressures in patients with cirrhosis of liver and non-cirrhotic portal fibrosis
}

\author{
S K SARIN, K K SETHI, AND R NANDA \\ From the Departments of Gastroenterology and Cardiology, GB Pant Hospital, New Delhi, India
}

SUMMARY In order to examine the relationship of various haemodynamic parameters in two different liver diseases, 10 patients with cirrhosis of liver and 14 patients with non-cirrhotic portal fibrosis were studied. In cirrhotics, mean $( \pm S D)$ wedged hepatic $(25 \cdot 8 \pm 6 \cdot 4 \mathrm{~mm} \mathrm{Hg})$, intrahepatic $(24.5 \pm 6 \cdot 2 \mathrm{mmHg})$ and intrasplenic $(25 \cdot 0 \pm 5 \cdot 6 \mathrm{mmHg})$ pressures correlated significantly $(\mathrm{p}<0 \cdot 001)$ with intravariceal $(25 \cdot 2 \pm 6 \cdot 7)$ pressure measurements. In patients with NCPF, mean $( \pm S D)$ wedged hepatic $(9 \cdot 1 \pm 3.7 \mathrm{mmHg})$ and intraphepatic $(15.4 \pm 5.8 \mathrm{mmHg})$ pressures were significantly $(\mathrm{p}<0.01)$ lower than the intrasplenic $(24.5 \pm 4.2 \mathrm{mmHg})$ and intravariceal $(23.96 \pm 5.6 \mathrm{mmHg})$ pressures. Two independent pressure gradients, one between intrasplenic and intrahepatic pressure $(8.9 \pm 6.5 \mathrm{mmHg})$ and another between intrahepatic and wedged hepatic venous pressure $(6 \cdot 2 \pm 5 \cdot 6 \mathrm{mmHg})$ were seen in non-cirrhotic portal fibrosis patients, indicating the likelihood of both pre- and perisinusoidal resistance to flow of portal venous blood in these patients. A highly significant $(\mathrm{p}<0 \cdot 001)$ correlation between intravariceal and intrasplenic pressures was found in patients with cirrhosis of liver $(r=0.93)$, as well as in patients with non-cirrhotic portal fibrosis $(r=0 \cdot 85)$. No correlation was found between the size of oesophageal varices and wedged hepatic and intrahepatic pressures. Patients with grade 4 varices had significantly higher intravariceal $(\mathrm{p}<0 \cdot 01)$ and intrasplenic $(\mathrm{p}<0 \cdot 05)$ pressure than patients with grade 2 varices. It can be concluded that intravariceal pressure is representative of portal pressure in patients with cirrhosis of liver as well as in non-cirrhotic portal fibrosis patients and it can be recommended as the single haemodynamic investigation in patients with portal hypertension and oesophageal varices.

Conventional techniques used for the assessment of portal pressure have included wedged hepatic vein pressure, umbilical vein catheterisation, direct portal vein pressure measurement at surgery and intrasplenic pressure recording.' Intrahepatic pressure measurement with the help of a thin needle has also been found to be a simple and equally sensitive method as wedged hepatic vein pressure measurement in patients with alcoholic cirrhosis. ${ }^{2}$ All these methods are, however, invasive and do not reflect the precise pressure inside the oesophageal varices. In

Address for correspondence: Dr S K Sarin. Assistant Professor. Department of Gastroenterology. GiB Pant Hospital. New Delhi 2. India.

Received for publication 20 Junc 1986 a recent study, variceal pressure was measured indirectly with the help of a pneumatic pressure sensor device fitted to an endoscope and was found to correlate well with the superior mesenteric vein pressure measured at surgery. ${ }^{3}$ Dawson et al using the same technique reported a significant correlation between variceal pressure and wedged hepatic vein pressure in patients with alcoholic cirrhosis. ${ }^{+}$These observations have, however, not been further validated. Moreover, little information is available on the interrelationship of intravariceal pressure with intrasplenic, wedged hepatic vein pressure and intrahepatic pressure in patients with cirrhosis of liver.

Non-cirrhotic portal fibrosis is a common cause of 
portal hypertension in India and Japan. ${ }^{-\infty}$ The aetiopathogenesis of this disease is poorly understood. The patients generally present with splenomegaly and a history of recurrent variceal bleeding. ${ }^{5}$ The few haemodynamic studies available on non-cirrhotic portal fibrosis patients give conflicting and inadequate information. ${ }^{51-11}$ The present study was designed to measure the different haemodynamic parameters in patients with cirrhosis of liver and in non-cirrhotic portal fibrosis patients. An attempt was also made to find out the correlation between the various haemodynamic measurements in the two groups of patients.

\section{Methods}

PATIENTS

Twenty four patients with portal hypertension, 10 with cirrhosis (eight men, two women, mean age $36 \cdot 6 \pm 7.9$ years) of the liver and 14 with non-cirrhotic portal fibrosis (nine men, five women, mean age $29 \cdot 3 \pm 4 \cdot 7$ years) were investigated. The diagnosis of cirrhosis was made at histopathology in all the patients. Of the 10 patients, five each had alcoholic and posthepatitic or cryptogenic cirrhosis. All the patients belonged to Child's A category of liver disease. None had a past history of ascites, hepatic encephalopathy or was receiving beta blocking agents. The diagnosis of non-cirrhotic portal fibrosis was based on the criteria described earlier ${ }^{12}-$ that is, in a patient with portal hypertension, presence of dilated and patent splenic and portal veins and no evidence of cirrhosis at liver biopsy. Grading of oesophageal varices was done from 1 to $4 .{ }^{13}$ Grade 2 varices were seen in seven (cirrhosis three, noncirrhotic portal fibrosis four), grade 3 in seven (cirrhosis three, non-cirrhotic portal fibrosis four) and grade 4 in 10 (cirrhosis four, non-cirrhotic portal fibrosis six) patients.

\section{HAEMODYNAMIC INVESTIGATIONS}

All patients were told about the nature of the study and the protocol of investigations, and their informed written consent was obtained. The procedures were all done at one sitting and in the same order, a minimum of 15 days after cessation of variceal bleeding and when haemoglobin value was greater than $8.0 \mathrm{~g} / \mathrm{dl}$. After a minimum fast of six hours, a $7 \mathrm{~F}$ Goddale-Lubin catheter was introduced percutaneously under local anaesthesia into the lumen of the femoral vein with the help of a vessel dilator and polypropylene sheath according to the Seldinger method. Pressures were recorded using a fluid filled transducer and a multichannel ink jet recorder Mingograph (Siemens-Elema), on a paper running at $1 \mathrm{~mm} / \mathrm{sec}$. An electronic mean of the readings was taken. The zero reference level for all the pressure measurements was set at $5 \mathrm{~cm}$ below the sternal angle. The catheter was wedged in the right lateral and inferior area of the liver shadow under fluroscopic control as suggested by Valla $e t$ al. ${ }^{11}$ Wedging in a hepatic vein was considered to be satisfactory when the following criteria were fulfilled: (a) stable pressure curve; (b) absence of reflux after injection of $2 \mathrm{ml}$ contrast material into the catheter; (c) sharp fall in pressure upon withdrawal of the catheter. Heparinised saline was flushed after two minutes to obviate the possible vasospastic effects of the contrast injection. An identical value in two hepatic venules was considered as the correct wedged hepatic vein pressure and was recorded.

Intrahepatic interstitial pressure was measured by inserting into the liver parenchyma a Chiba needle (23-15.0 DCN, Cook Bloomington Inc, Markhem, Ontario, Canada) under fluoroscopic control. The needle was flushed clean and filled with saline and connected to a recorder for measurement of interstitial pressure. If the patient was apprehensive and was hyperventilating (only two patients), $5-10 \mathrm{mg}$ diazepam was given intravenously and the procedure was repeated. A mean of two to three measurements, recorded from at least two different areas within the liver was taken as the intrahepatic pressure. Intrasplenic pressure was similarly recorded with the help of a Chiba needle.

Intravariceal pressure was recorded with a simple Teflon catheter which had been used earlier as a variceal injector. " ${ }^{15}$ After insertion through the endoscopic channel, the injector, filled with absolute alcohol was made to puncture a variceal column approximately $5 \mathrm{~cm}$ above the cardia. As blood flows up into the injector immediately on puncturing the vein because of high intravariceal pressure, it ensures a proper intravariceal placement of the injector needle. As absolute alcohol is an aqueous solution and has nearly the same specific gravity as water, it was used as a fluid medium for measuring variceal pressure. In five successive blinded procedures, no difference was found between the pressure recorded by using absolute alcohol or normal saline $(0.9 \%)$ in the injector. Intravariceal pressure was recorded while the patient was breathing normally without any retching, by connecting the injector to the fluid filled transducer. A mean of a minimum of three readings was obtained. Intra-oesophageal pressure was measured simultaneously by means of a manometer line attached to the endoscope and was used as an internal zero reference point from which the varix pressure was recorded. After measuring the pressure from the second varix (in two patients after the third varix) proper sclerotherapy of all varices was carried out. ${ }^{.1510}$ 
STATISTICAL. ANALYSIS

$t$-Test for independent samples and one way analysis of variance for unequal group sizes followed by multiple range test were used. Inter-relationship of various haemodynamic parameters were studied by Karl-Pearson's coefficient of correlation. The various observations are presented as mean ( $\pm \mathrm{SD})$.

\section{Results}

The mean $( \pm S D)$ wedged hepatic vein pressure and intrahepatic pressures in patients with cirrhosis were $25 \cdot 8 \pm 6 \cdot 42 \mathrm{~mm}$ and $24 \cdot 5 \pm 6 \cdot 2 \mathrm{mmHg}$ respectively. There was no significant difference between the two means. In fact, in eight of 10 patients with cirrhosis, the difference between wedged hepatic vein pressure and intrahepatic pressure was less than $3 \mathrm{mmHg}$ and a good positive correlation $(r=0.85, p<0 .(01)$ was observed between the two (Fig. 1). Although, in two patients with cryptogenic cirrhosis, a difference of more than $3 \mathrm{mmHg}$ between the wedged hepatic vein pressure and intrahepatic pressure measurement was seen, the difference between the mean $( \pm S D)$ wedged hepatic vein pressure and intrahepatic pressures in patients with the two types of cirrhosis was not significant. In non-cirrhotic portal fibrosis patients, the mean $( \pm S D)$ wedged hepatic vein pressure was $9.14 \pm 3.66 \mathrm{mmHg}$. In half of the patients, the wedged hepatic vein pressure was 8 or $<8 \mathrm{mmHg}$. Wedged hepatic venous pressure was significantly $(p<0 \cdot 05)$ lower than the intrahepatic pressure $(15 \cdot 36 \pm 5 \cdot 57)$ in non-cirrhotic portal fibrosis patients (Fig. 2). In nearly two-thirds $(64 \cdot 3 \%)$ of patients, the difference between the wedged hepatic vein pressure and intrahepatic pressure measurement was more than $3 \mathrm{mmHg}$ and a poor correlation $(r=0.32)$ was found between the two (Fig. 1).

In patients with cirrhosis of liver, a highly significant $(\mathrm{p}<0 \cdot()(0)$ ) correlation was seen between wedged hepatic vein pressure and intrasplenic $(r=0.96)$ and intravariceal pressures $(r=0 \cdot 92)$ (Figs 3-5). Intrahepatic pressure also correlated significantly $(\mathrm{r}=0.86, \mathrm{p}<(0 \cdot(0) 1)$ with intravariceal pressure in these patients. There was no difference between patients with alcoholic cirrhosis and cryptogenic cirrhosis. In patients with non-cirrhotic portal fibrosis, mean $( \pm S D)$ wedged hepatic vein pressure and intrahepatic pressures were significantly $(p<0 \cdot(01)$ lower than the splenic and variceal pressures with a very poor correlation between them (Figs 2, 3, 5).

Mean ( \pm SD) intravariceal and intrasplenic pressures in cirrhotics were $25 \cdot 2 \pm 6 \cdot 73$ and $25 \cdot() \pm 5 \cdot 64$ $\mathrm{mmHg}$ respectively and in non-cirrhotic portal fibrosis patients $23.96 \pm 5.58$ and $24.5 \pm 4.23 \mathrm{mmHg}$ respectively. There were no significant differences between the means. A highly significant correlation

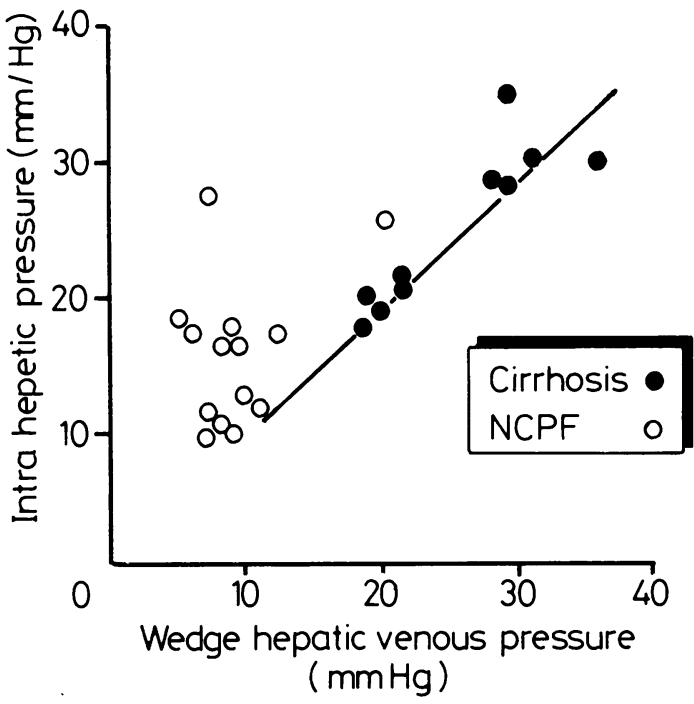

Fig. 1 Wedged hepatic venous pressure and intrahepatic pressure in patients with cirrhosis of liver and non-cirrhotic portal fibrosis. A significant $(p<0 \cdot 01)$ positive correlation was seen between the two in patients with cirrhosis.

between intravariceal and intrasplenic pressure was observed in patients with cirrhosis $(r=0.93, p<0 \cdot(0) 1)$ as well as in non-cirrhotic portal fibrosis patients $(\mathrm{r}=0.85, \mathrm{p}<0 \cdot(001)$ (Fig. 6). In eight of 10 patients with cirrhosis and 12 of $14(85 \cdot 7 \%)$ patients with non-

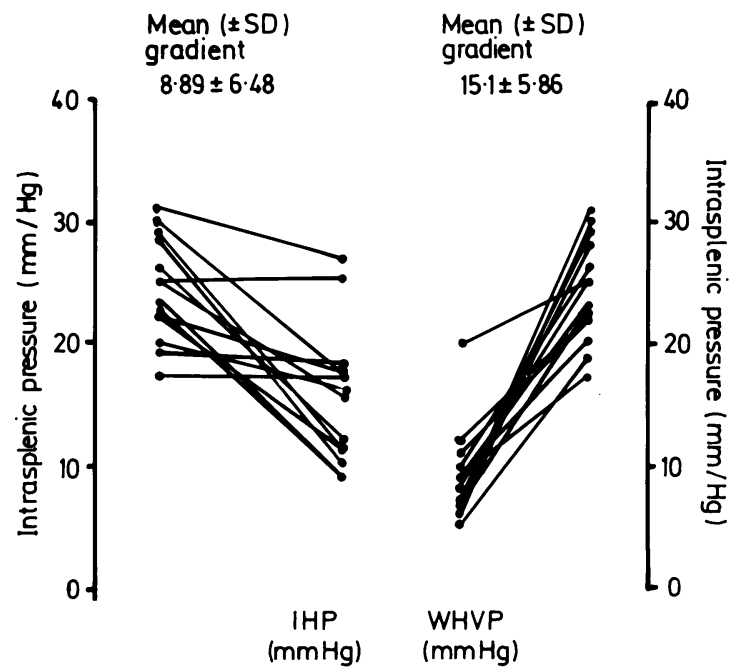

Fig. 2 Intrasplenic, intrahepatic (IHP) and wedged hepatic venous pressures (WHVP) in patients with non-cirrhotic portal fibrosis. The mean $( \pm S D)$ gradient between intrasplenic and intrahepatic pressure was $8.89 \pm 6.48 \mathrm{~mm} \mathrm{Hg}$ and between intrasplenic and WHVP was $15 \cdot 1 \pm 5 \cdot 86 \mathrm{mmHg}$. 


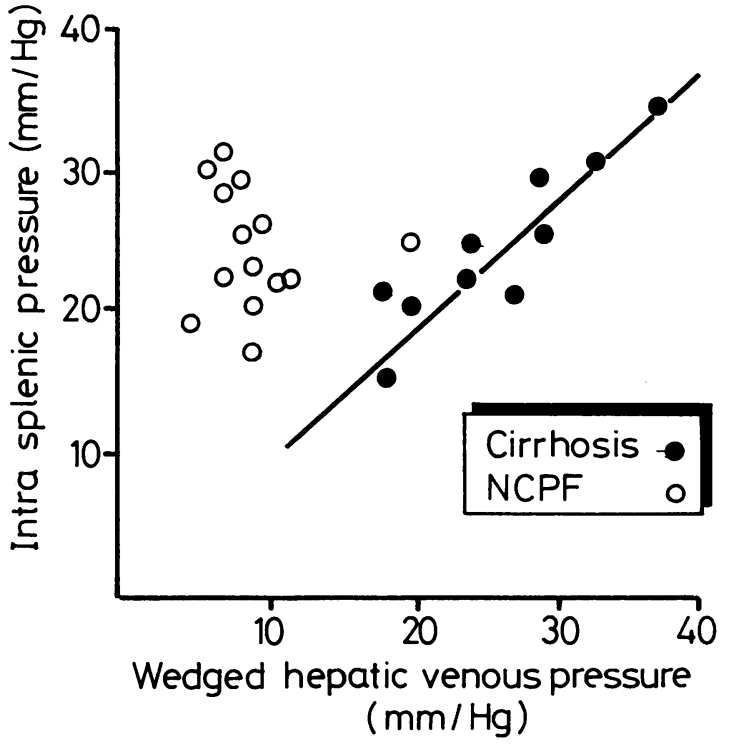

Fig. 3 Wedged hepatic and intrasplenic pressures in patients with cirrhosis and non-cirrhotic portal fibrosis. A highly significant $(p<0.001)$ correlation $(r=0.96)$ was seen between the two in cirrhotics.

cirrhotic portal fibrosis, the differences between the intravariceal and intrasplenic pressure measurements were 3 or $<3 \mathrm{mmHg}$.

The mean $( \pm S D)$ pressure gradients between intrasplenic and wedged hepatic vein pressure and intrasplenic and intrahepatic pressures in noncirrhotic portal fibrosis patients were $15 \cdot 1 \pm 5 \cdot 86$ and $8 \cdot 89 \pm 6 \cdot 48 \mathrm{mmHg}$ respectively (Fig. 2). A gradient of $6 \cdot 21 \pm 5.58 \mathrm{mmHg}$ between intrahepatic and wedged hepatic vein pressure was also observed in patients with non-cirrhotic portal fibrosis.

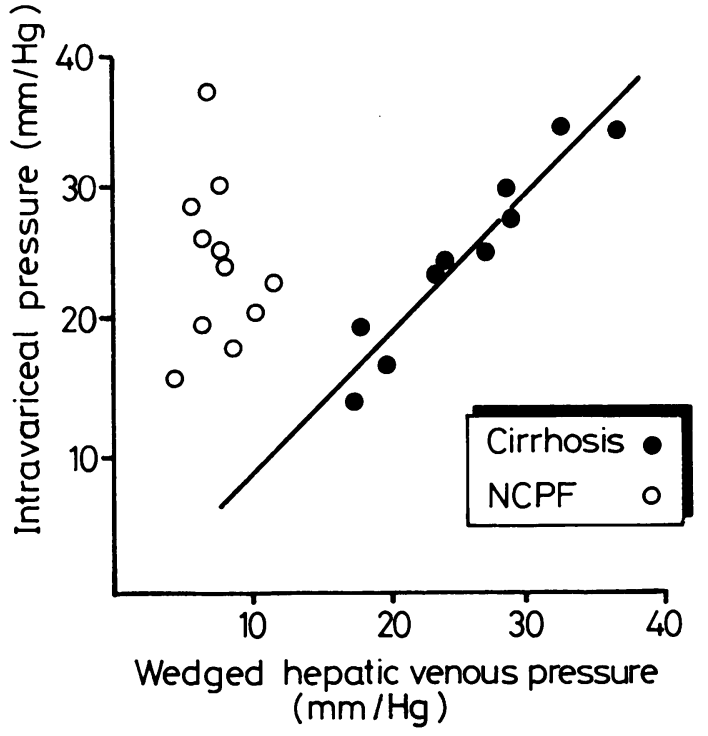

Fig. 5 Wedged hepatic and intravariceal pressures in patients with cirrhosis and non-cirrhotic portal fibrosis. A highly significant $(p<0.001)$ correlation was observed between the two, in patients with cirrhosis.

Hepatic vein pressure gradient (determined by substracting the free hepatic venous pressure from wedged hepatic vein pressure) was $16 \cdot 6 \pm 5.37 \mathrm{mmHg}$ in patients with cirrhosis and $4 \cdot 18 \pm 2 \cdot 17 \mathrm{mmHg}$ in non-cirrhotic portal fibrosis patients.

There were no significant differences in the various haemodynamic measurements between patients with grade 2,3 , and 4 varices except that in patients with grade 4 varices, intrasplenic and intravariceal pressures were significantly higher than in patients with grade 2 varices (Table).

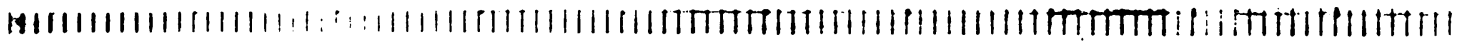

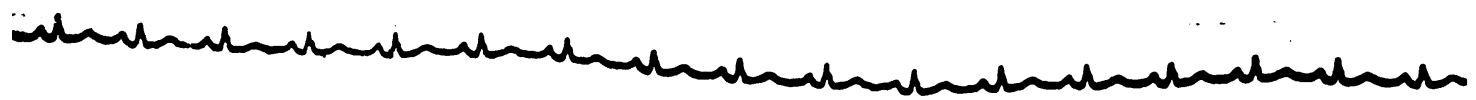

Intra variceal (37)

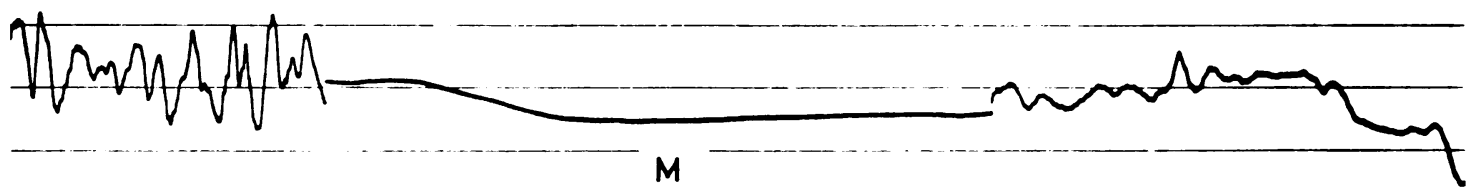

Fig. 4 Photograph of the actual intravariceal pressure recording. $M=$ Mean. 


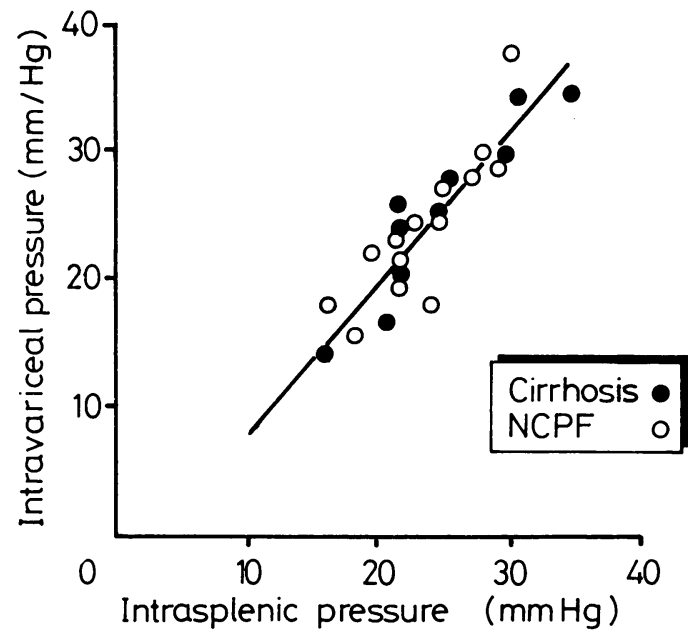

Fig. 6 Intrasplenic and intravariceal pressures in patients with cirrhosis and non-cirrhotic portal fibrosis. A highly significant $(p<0 \cdot 001)$ correlation was seen between the two in cirrhosis as well as non-cirrhotic portal fibrosis patients.

\section{Discussion}

Techniques for measuring intrasplenic, wedged hepatic, intrahepatic and portal vein pressures are invasive and need lot of skill. ${ }^{x 17-21}$ Mosimann has recently shown the sensitivity and usefulness of a non-invasive technique for intravariceal pressure measurement using a pneumatic pressure sensor device fitted to an endoscope. ${ }^{34}$ Besides the nonavailability of this device, measurements with this technique are likely to be affected by variation in respiration, heart beat, oesophageal wall pressure and compliance of the variceal wall tissue. The possibility of the pressure sensor getting dislodged from the varix during oesophageal peristalsis can also alter the observations. ${ }^{+}$The technique of direct intravariceal pressure measurement described in the present study, requires no special equipment. In fact,

Table Mean $\left( \pm S D\right.$ ) pressures (in $\mathrm{mmHg}^{\mathrm{m}}$ ) in patients* with different grades of oesophageal varices

\begin{tabular}{lllll}
\hline $\begin{array}{l}\text { Grade of } \begin{array}{l}\text { Wedged } \\
\text { varices } \\
\text { hepatic } \\
\text { venous } \\
\text { pressure }\end{array} \\
\text { pressure }\end{array}$ & $\begin{array}{l}\text { Intrahepatic } \\
\text { pressure }\end{array}$ & $\begin{array}{l}\text { Intrasplenic } \\
\text { pressure }\end{array}$ & $\begin{array}{l}\text { Intravariceal } \\
\text { pressure }\end{array}$ \\
\hline 2 & $15 \cdot 42 \pm 6 \cdot 37$ & $15 \cdot 71 \pm 8 \cdot 56$ & $21 \cdot 64 \pm 2 \cdot 78$ & $19 \cdot 71 \pm 3 \cdot 68$ \\
3 & $16 \cdot 00 \pm 11 \cdot 37$ & $19 \cdot(0) \pm 5 \cdot 83$ & $24 \cdot 42 \pm 5 \cdot 56$ & $23 \cdot 71 \pm 5 \cdot 62$ \\
4 & $16 \cdot 60 \pm 11 \cdot 25$ & $21 \cdot 7 \pm 8 \cdot 35$ & $26 \cdot 7 \pm 4 \cdot 52 \dagger$ & $28 \cdot 35 \pm 5 \cdot 14 \dagger$ \\
\hline
\end{tabular}

*Includes all 24 patients (both non-cirrhotic portal fibrosis and cirrhosis) with portal hypertension: $†$ Patients with grade 4 varices had significantly higher mean intrasplenic $(\mathrm{p}<0 \cdot(05)$ and intravariceal $(p<0 \cdot(01)$ pressures compared with patients with grade 2 varices. it can be carried out easily before doing routine intravariceal sclerotherapy. A definite variceal puncture and in turn, intravariceal pressure measurement, is ensured using a transparent Teflon injector, in which the blood can be seen to flow up immediately on puncturing a varix..$^{15} 162$

Intravariceal pressure was found to have a highly significant $(p<0.001)$ correlation with wedged hepatic, intrahepatic, and intrasplenic pressure in patients with cirrhosis. While it is well known that in cirrhotics, intrasplenic pressure correlates well with wedged hepatic vein pressure and wedged hepatic vein pressure correlates closely with intrahepatic pressure, ${ }^{1 \infty-21}$ the fact that intravariceal pressure can reliably reflect the wedged hepatic vein pressure and intrasplenic pressure, as seen by us, has not been adequately documented in the past.

A linear $(p<0 \cdot 01)$ correlation was seen between wedged hepatic vein pressure and intrahepatic pressure in patients with cirrhosis of liver. No significant difference was seen between patients with alcoholic and posthepatitic or cryptogenic cirrhosis. Reynolds et al had also reported no difference in wedged hepatic vein pressure and portal vein pressure in patients with alcoholic liver disease, cryptogenic cirrhosis, and chronic active hepatitis.21 Others, however, believe that in non-alcoholic cirrhosis, wedged hepatic vein pressure is lower than intrahepatic pressure and it underestimates portal pressure. ${ }^{123}$

Non-cirrhotic portal fibrosis, sometimes called idiopathic portal hypertension and hepatoportal sclerosis, ${ }^{2+}$ is a relatively benign variety of portal hypertension, of ill-understood aetiopathogenesis. The precise anatomical location of the resistance to flow of portal blood in patients with non-cirrhotic portal fibrosis is not known. Two specific pathological lesions observed in this disease include (i) occlusive changes in the intrahepatic portal vein radicles, which are focal in distribution, ${ }^{25}$ and (ii) diffuse collagenisation of the space of Disse..$^{26} \mathrm{~A}$ few haemodynamic studies done in the past in patients with non-cirrhotic portal fibrosis have shown variable results. ${ }^{541127}$ Sama et al had reported a mean $( \pm S D)$ wedged hepatic vein pressure of $12 \cdot 7 \pm 6 \cdot 16 \mathrm{mmHg}$ in patients with non-cirrhotic portal fibrosis, which was significantly $(p<0 \cdot 001)$ higher than the controls. ${ }^{8}$ They found raised wedged hepatic vein pressure in 40 of their $44(91 \%)$ patients. Williams et al have also reported raised wedged hepatic vein pressure, though in a smaller proportion $(52 \%)$ of patients." The mean $( \pm \mathrm{SD})$ wedged hepatic vein pressure of $9.14 \pm 3.66 \mathrm{mmHg}$ detected in the present study, is relatively lower than that reported in the earlier studies. ${ }^{9}$ " 10 In half of our non-cirrhotic portal fibrosis patients, wedged hepatic vein pressure was 8 or $<8$ 
$\mathrm{mmHg}$. The difference in the various studies could be because of the wide variations seen in the distribution and the extent of morphological changes occuring at the two possible pathological sites of haemodynamic block. While occlusive pyelephlebitic changes, ${ }^{5}$ also known as obliterative portovenopathy, ${ }^{25}$ can explain the presinusoidal resistance, the rise in wedged hepatic vein pressure seems to result from changes occuring in the sinusoids, secondary to diminished portal venous flow and compensatory increased hepatic arterial flow. ${ }^{27}$

In the present series, the patients with noncirrhotic portal fibrosis had a significantly $(\mathrm{p}<0.01)$ lower mean wedged hepatic vein pressure, compared with the patients with cirrhosis of liver. This could be due to the relatively milder perisinusoidal fibrosis and compression seen in the non-cirrhotic portal fibrosis patients. ${ }^{23}$ Okuda et al have also observed that wedged hepatic vein pressure significantly underestimates portal pressure in non-cirrhotic portal fibrosis patients. ${ }^{5}$ A poor correlation was seen between wedged hepatic, intrahepatic and intrasplenic pressures in our patients with non-cirrhotic portal fibrosis. Intravariceal pressure on the other hand, was seen to bear an excellent linear relationship with intrasplenic pressure.

A gradient between intrasplenic pressure and wedged hepatic vein pressure in non-cirrhotic portal fibrosis patients has been documented in the past. ${ }^{5810}$ In our study, the gradient between intrasplenic pressure and wedged hepatic vein pressure was $15 \cdot 1 \pm 5 \cdot 86 \mathrm{mmHg}$. Such a gradient could possibly result from the combined effect of presinusoidal and perisinusoidal resistance to flow of portal blood. In fact, two independent gradients, one between intrasplenic and intrahepatic pressure $(8.8 \pm 6.48 \mathrm{mmHg})$ and another between intrahepatic pressure and wedged hepatic vein pressure $(6 \cdot 21 \pm 5.58 \mathrm{mmHg})$ could be identified. While demonstration of the former gradient clearly outlines haemodynamically the presence of a presinusoidal block, the existance of the later gradient reflects a perisinusoidal resistance to flow of portal blood in patients with noncirrhotic portal fibrosis. On the basis of these two gradients one can explain the poor correlation between wedged hepatic, intrahepatic, and intrasplenic pressures in patients with non-cirrhotic portal fibrosis.

No correlation was found between the size of oesophageal varices and wedged hepatic vein pressure and intrahepatic pressure. Patients with grade 4 varices, however, had significantly higher intravariceal $(p<0 \cdot 01)$ and intrasplenic $(p<0 \cdot 05)$ pressures than patients with grade 2 varices. There was no difference in any of the pressures between patients with grade 3 and grade 4 varices. Two recent studies have not found any correlation between the size of varices and the hepatic venous pressure gradient. ${ }^{2 \times 29}$

Our results clearly indicate that intravariceal pressure correlates closely with intrasplenic pressure in patients with cirrhosis of liver and in non-cirrhotic portal fibrosis patients. In cirrhotics, variceal pressure can also reliably reflect wedged hepatic vein pressure and intrahepatic pressure. In patients with non-cirrhotic portal fibrosis, however, both wedged hepatic vein pressure and intrahepatic pressure measure significantly lower pressures than intrasplenic and intravariceal pressures. Direct intravariceal pressure measurement, besides being simple, can be recommended as the single haemodynamic investigation for assessing accurately portal pressure in patients with non-cirrhotic portal fibrosis.

This study was partly financed by grants received from the Indian Council of Medical Research. We are grateful to Dr K R Sundaram, Department of Biostatistics, All India Institute of Medical Sciences for extending help with the analysis of the data.

\section{References}

1 Groszmann RJ. Reassessing portal venous pressure measurements. [Editorial]. Gastroenterology 1984; 86: 1611-7.

2 Orrego H, Blendis LM, Crossley IR, et al. Correlation of intrahepatic pressure with collagen in the Disse space and hepatomegaly in humans and in the rat. Gastroenterology 1981; 81: 546-8.

3 Mosimann R. Non-aggressive assessment of portal hypertension using endoscopic measurement of variceal pressure. Am J Surg 1982; 143: 212-4.

4 Dawson J, Gertach P, Mosimann R, West R, Elias E. Endoscopic variceal pressure measurements: response to isosorbide dinitrate. Gut 1985; 26: 843-7.

5 Okuda K, Kono K, Ohnishi K, et al. Clinical study of eighty six cases of idiopathic portal hypertension and comparison with cirrhosis with splenomegaly. Gastroenterology 1984; 86: 60)-10.

6 Sarin SK, Sachdev G, Nanda R, Vij JC, Anand BS. Endoscopic sclerotherapy using absolute alcohol. Gut 1985; 26: 120-4.

7 Anand CS, Tandon BN, Nundy S. The causes, management and outcome of upper gastrointestinal haemorrhage in an Indian hospital. Br J Surg 1983; 70: 209-11.

8 Sama SK, Bhargava S, Gopinath N, et al. Non-cirrhotic portal fibrosis. Am J Med 1971; 51: 160-9.

9 Iber FL. Obliterative portovenopathy of the liver and idiopathic portal hypertension. Ann Intern Med 1969; 71: 66()$-1$.

10 Williams R, Parsonson A, Somers K, Hamilton JPS. Portal hypertension in idiopathic tropical splenomegaly. Lancet 1966; 1: 329-33.

11 Boyer JL, Sen Gupta KP, Biswas SK, et al. Idiopathic portal hypertension. Comparison with the portal hyper- 
tension of cirrhosis and extrahepatic portal vein obstruction. Ann Intern Med 1967; 66: 41-68.

12 Sarin SK. Nundy S. Subclinical encephalopathy after portasystemic shunt in patients with non-cirrhotic portal fibrosis. Liver 1985; 5: 142-6.

13 Conn HO. Ammonia tolerance in the diagnosis of oesophageal varices. A comparison of the endoscopic, radiologic and biochemical techniques. J Lab Clin Med 1967; 70: 442-51.

14 Valla D, Bercoff E, Menu Y, Bataille C, Lebrec D. Discrepancy between wedged hepatic venous pressure and portal venous pressure after acute propranolol administration in patients with alcoholic cirrhosis. Gastroenterology 1984; 86: 1400-3.

15 Sarin SK, Sachdev G, Nanda R, Batra SK, Anand BS. A comparison of the two time schedules of endoscopic sclerotherapy: a prospective randomized controlled study. Gut 1986; 27: 710-3.

16 Sarin SK, Nanda R, Gaur SK, Kumar N, Vij JC, Anand BS. Repeated injection sclerotherapy for patients with continued active variceal bleeding. Ann Surg 1985; 202: 208-11.

17 Atkinson M. Sherlock S. Intrasplenic pressure as an index of portal venous pressure. Lancet 1954; 1: 1325-7.

18 Vennes JA. Transhepatic pressure measurements. Ann NY Acad Sci 1970; 170: 193-200.

19 Orrego H, Amenabar E, Lara G, et al. Measurement of intrahepatic pressure as index of portal pressure. $\mathrm{Am} \mathrm{J}$ Med Sci 1964; 247: 278-82.

20) Reynolds TB, Ito S, Iwatsuki S. Measurement of portal pressure and its clinical application. Am J Med 1970); 49: $649-57$.
21 Pomier Layarargues G, Kusielewicz D, Willems B, et al. Presinusoidal portal hypertension in non-alcoholic cirrhosis. Hepatology 1985; 5: 415-8.

22 Sarin SK, Nanda R, Vij JC, Anand BS. Oesophageal ulcerations after endoscopic sclerotherapy, a complication or an accompaniment? Endoscopy 1986; 18: 44-5.

23 Shibayama Y. Nakata K. Localization of increased hepatic vascular resistance in liver cirrhosis. Hepatology 1985; 5: 643-8.

24 Mikkelsen WP, Edmondson HA, Peters RL, Redeker AG, Reynolds TB. Extra and intrahepatic portal hypertension without cirrhosis (hepatoportal sclerosis). Ann Surg 1965; 162: 6()2-20.

25 Nayak NC, Ramalingaswami V. Obliterative portovenopathy of the liver associated with so-called idiopathic portal hypertension in tropical splenomegaly. Arch Pathol (Chic) 1969; 87: 359-69.

26 Tandon BN, Lakshminarayanan R, Bhargava S, Nayak NC, Sama SK. Ultrastructure of the liver in noncirrhotic portal fibrosis with portal hypertension. Gut 1970; 11: 9(05-10.

27 Iber FL. The cause of portal hypertension. Am J Med Sci 1968; 255: 217-20.

28 Lebrec D, De Fleury P, Rueff B, et al. Portal hypertension, size of oesophageal varices and risk of gastrointestinal bleeding in alcoholic cirrhosis. Gastroenterology 1980; 79: 1139-44.

29 Garcia-Tsao G, Groszmann RJ, Fisher RL, Conn HO, Atterbury CE, Glickman M. Portal pressure, presence of oesophageal varices and variceal bleeding. Hepatology 1985; 5: 419-24. 